\title{
Design of Scotch Yoke Hacksaw Cutting Machine
}

\author{
Tikaram Patil $^{1}$, Ketan Talele ${ }^{2}$, Kirtikumar patil ${ }^{3}$, Rohit khambayat ${ }^{4}$, Tushar A. Koli ${ }^{5}$ \\ ${ }^{1,2,3,4} U G$ student, Department of Mechanical Engineering, GCOE, Jalgaon, India \\ ${ }^{5}$ Assistant Professor, Department of Mechanical Engineering, GCOE, Jalgaon, India
}

Received on: 16 July,2021

Revised on: 22 August, 2021

Published on: 24 August, 2021

\begin{abstract}
The objective of this work is to automate the conventional power hacksaw machine in order to achieve high productivity of work-pieces than the power hacksaw machine using a Double hacksaw blade. The operator need not measure the length of the work-piece that is to be cut. The machine feeds the work-piece with the help of a shaft, which is driven by a DC motor. A DC motor is used to bring about the reciprocating motion required for cutting the work-pieces. With the help of this multi-way power hacksaw machine, the four metal bars can be cut simultaneously to get the high-speed cutting rate and to achieve mass production for maximum profit in related companies. This project is very much useful and easy to install by the user and also the motor used will not only operate with the help of electricity but also through conventional source of energy like solar energy.
\end{abstract}

Keywords- Scotch Yoke Mechanism, fabrication, sliding mechanism, double acting hacksaw, Designing.

\section{I -INTRODUCTION}

$\mathbf{I}_{\mathrm{n}}$ present condition many electrically operated power hacksaw machines of different companies with different specifications are available for the use in the shop floor. These machines are so precise that they can cut metal bars with minimum time made up of different materials but they have one and major disadvantage that those are able to cut a single piece of the bar at a time. For industries to achieve the mass production, it is necessary to cut metal bars with high rate. So it is impossible to depend upon conventional single frame power hacksaw machines and need the improvement in technology and design of such machines. With the help of this multi-way power hacksaw machine, the four metal bars can be cut simultaneously to get the highspeed cutting rate and to achieve mass production for maximum profit in related companies. As this machine overcomes all the limitations and drawbacks of conventional hacksaw machines, it is also helpful for small-scale industries due to its simple working and operating conditions along with its compatibility, efficiency and affordable price. This project is about cutting the wood, metal, pipe, angle, channel, flat plates, rods and such other things. This project is very much useful and easy to install by the user. However, the author's name can be used along with the reference number in the running text. The order of reference in the running text should match with the list of references at the end of the paper.

\section{II- LITERATURE REVIEW}

\subsection{Definition}

Hacksaw Machines offered by us are used for metal cutting ranging from transportable model to giant size machine. Owing to smooth \& speedy functioning abilities, these hacksaw machines operations spontaneously for aiding the worker in consistently carrying his work with ultimate competence. A sewing machine is a machine tool designed to cut material to a desired length or contour. It functions by drawing a blade containing cutting teeth through the workpiece. The sewing machine is faster and easier than a hand 


\section{International Journal of Innovations in Engineering and Science, www.ijies.net}

saw and is used principally to produce an accurate square or metered cut on the workpiece.

\subsection{Scotch Yoke Mechanism}

The scotch yoke is a mechanism for converting the linear motion of a slider into rotational motion or viceversa. The piston or other reciprocating part is directly coupled to a sliding yoke with a slot that engages a pin on the rotating part. The shape of the motion of the piston is a pure sine wave over time given a constant rotational speed. The Scotch yoke (also known as slotted link mechanism) is a reciprocating motion mechanism, converting the linear motion of a slider into rotational motion, or vice versa. The piston or other reciprocating part is directly coupled to a sliding yoke with a slot that engages a pin on the rotating part. The location of the piston versus time is a sine wave of constant amplitude, and constant frequency is given a constant rotational speed. The term scotchyoke continues to be used when the slot in the yoke is shorter than the diameter of the circle made by the crank pin. For example, the side rods of a locomotive may have scotch yokes to permit vertical motion of intermediate driving axles.

\section{III- METHOLOGY}

The scotch yoke mechanism is constructed with iron bars. Here the crank is made in some length and the yoke is also made using the same material. It is noted that the minimum length of the yoke should be double the length of the crank. The crank and yoke are connected with a pin. Iron bars are welded to both sides of the yoke to get the reciprocating motion The yoke with the iron bars is fixed on the display board with the help of c clamp. Now the crank is welded to the end of the shaft of the motor. Now the pin on the crank is connected to the yoke.

\subsection{Hacksaw Machine-}

\subsubsection{Types of Hacksaw Machine}

- Light duty hacksaw machine.

- Hydraulic hacksaw machine.

- Power hacksaw machine.

- Circular band hacksaw machine.

- Horizontal swing type band saw machine.

- Band hacksaw machine.

- Jigsaw machine.

- Universal type circular hacksaw machine.

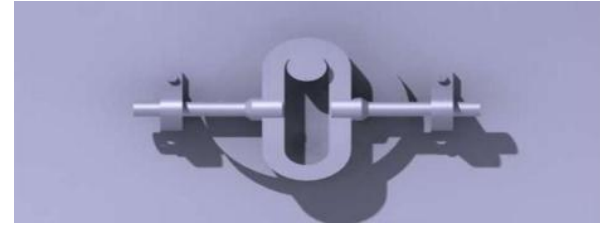

Fig -1: Scotch Yoke Mechanism

3.1.2 Working Principles Hacksaw Machine Using Scotch Yoke Mechanism

A hacksaw machine is work on the principle of SCOTCH YOKE MECHANISM in this rotary motion of the shaft is to be converted into the reciprocating motion of hacksaw frame. Working principle of hacksaw machine is very simple. First of all, the hacksaw machine is put on the ground and after that, whatever metal, wood, PVC, is cut is fixed on vice at required length, after that the electricmotor is connected with electricity. Now start the electric motor so due to that the shaft of the motor and the hollow disc will be rotated and also rotate the eccentric Centre and link connect to it. Due to rotation of links the hacksaw frame will be reciprocated on the metal and cutting of metal is done.

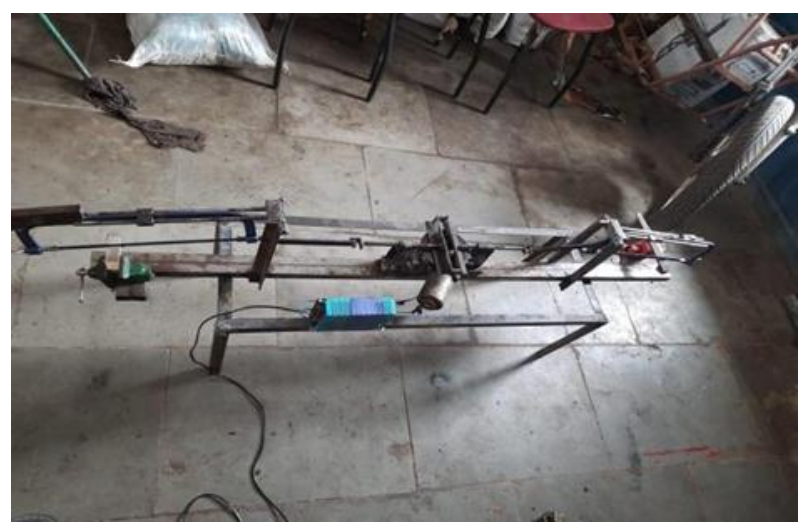

Fig -2: Hacksaw Machine

\subsubsection{Assembly of Hacksaw Machine-}

For assembly of hacksaw machine first of all on the base plate electric motor is mount vertically, the hollow disc having internal circle radius is same as the radius of the shaft of the motor is fiton the shaft and also the disc has an eccentric center, a metal bar is a weld at the eccentric center. The links one end is connected with the end of hacksaw frame and the second end is connected with the metal bar of eccentric centre. The buckle type elements are connected at the end of hacksaw frame and the link is connected to this buckle, pipe provides support to the hacksaw frame, the pipe is 


\section{International Journal of Innovations in Engineering and Science, www.ijies.net}

connected to thebase. Vice is also fit on the pipe and which also connect with the base.

\subsubsection{Features of Hacksaw Machine-}
a. Power efficiency.
b. High productivity.
c. Superb performance.
d. High operational fluency.
e. Sturdy and robust design

\subsection{Crank and Slider Mechanism-}

A crank is an arm attached at right angles to a rotating shaft by which reciprocating motion is imparted to or received from the shaft. It is used to convert circular motion into reciprocating motion or vice versa. The slider crank mechanism is used to transform rotational motion into transitional motion by means of rotating driving beam, connecting rod and sliding body.

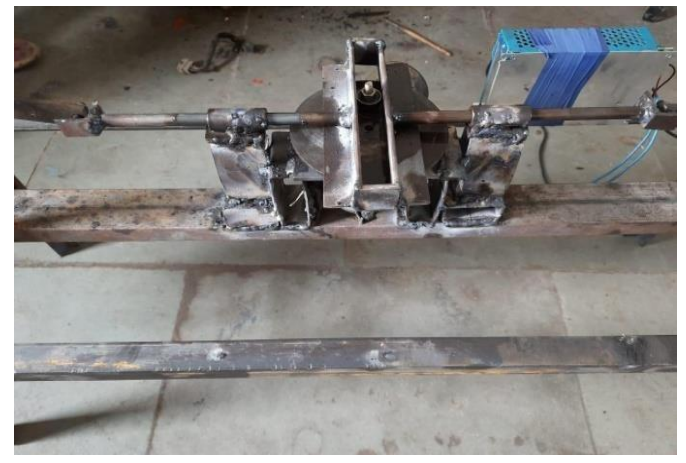

Fig.3. Crank and Slider Mechanism

\subsection{Consequence or Outcome}

The above discussion we conclude that to overcome problems in conventional hacksaw machine due to high efficiency, easy to operate. The proposed model of multi way hacksaw is helpful and complete all the expectations needed in the mini industries. As a result benefits would be achieved

Such as Longer tool life; easy chip flow and higher machining quality in the machining process. The selection of cutting fluid should be carefully carried out to obtain optimum result in machining process. Various factors are affecting the selection of cutting fluid type in machining operation such a type of work piece and the method of machining process.

\subsection{Hacksaw Blade}

\subsubsection{How to Use Power Hack Saw Blades Properly -} It is important to pay the same attention to power hack sawblades as to any other tools.

1. Keep the machine in good technical condition.
It is especially needed to check if: a. the lifting arm and its function are in order, b. oil pump of the lifting arm is cleanand without air bubbles.

2. Tighten the hack saw blade in the machine in correct position and straighten it properly.

3. Tighten the cutting material firmly into the clamps so that as many teeth as possible cut atleast 4 , maximum 30 ).

4. While bundle cutting (more pieces at once) make sureeach piece is firmly tightened.

5. While cutting metal castings make sure you remove foundry sand from the surface with bastard file or steel brush. Sand can cause the hack saw to run dull very fast.

6. While staring the machine, lower the saw frame carefully and change the pressure orlower the feed speed for several first cuts (only when new blade is used).

7. Do not use too high or too low pressure.

8. Always use cooling fluids while cutting.

\subsubsection{Technical Information for the Hacksaw Blade-}

How to Choose the Right Type of Hacksaw Blades Choosing of the hacksaw blade with the correct tooth number per inchdepends on dimensions and type of the cutting material. 14 teeth/ $25 \mathrm{~mm}$ - cutting of thin materials of all types as tubes, pipes, profiles etc. 10 teeth / $25 \mathrm{~mm}$ - cutting of all material types with small and medium dimensions 6 teeth $/ 25 \mathrm{~mm}$ - cutting of all material types of greater thickness 4 teeth $/ 25 \mathrm{~mm}$ cutting of soft material types of greater thickness.

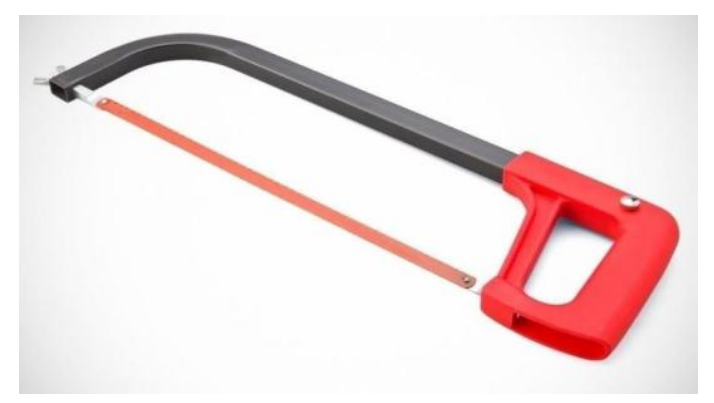

Fig.4. Hacksaw

\section{IV-MOTIVATION}

When we searching for our project in the market we show the demand of hacksaw blade is considerably increasing day by day with the growth of industrialization, engineering sector, real estate, automobile sector etc. It is used in almost every sector 


\section{International Journal of Innovations in Engineering and Science, www.ijies.net}

for cutting of materials like the angle, channel, flat plates, rods and such other things. It is also required in auto repair shops, general repairing workshops, fitting shops, welding shops and technical institutes. Govt. department of Railway, Defense, PWD, Postal \& Telegraph and others are one of the main users of it. In India large nos. of small enterprises are engaged in its manufacturing. By considering its demand, new production unit has a great prospect. So from that, we have concluded that the future base hacksaw machine is used for very costly machinery and in locomotives. The user can use this project in small industry, which cannot afford costly machinery.

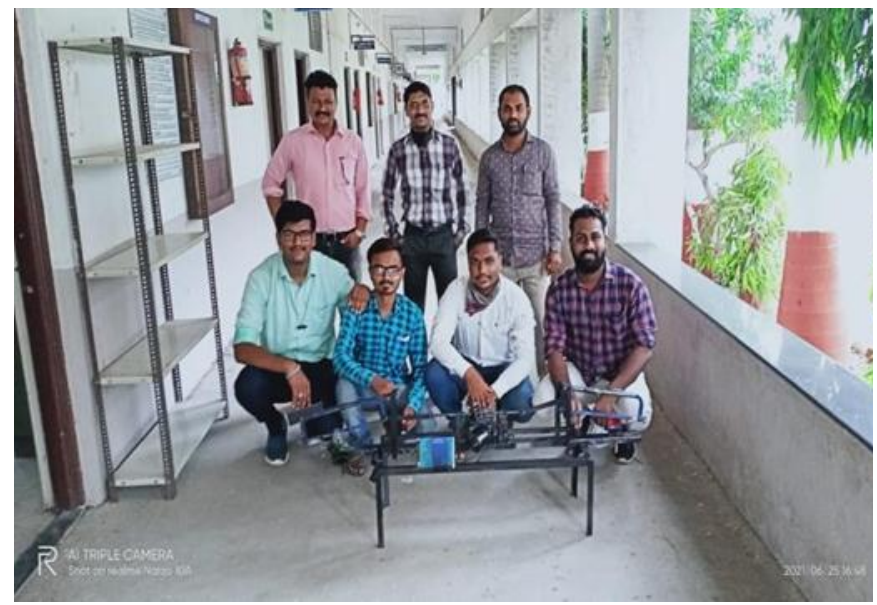

Fig.5- Photograph of Project.

\section{V- INDUSTRIAL PURPOSES-}

\section{Advantages-}

- The weight of the machine is less.

- It reduces the work of labour.

- Easy to make because of simple construction.

- High production rate.

- Cost is less.

- Easy maintenance and maintenance cost is less.

- It resists all atmospheric effects.

\section{Disadvantages-}

- Time consume more.

- Speed variation is required for cutting thedifferent metal

\footnotetext{
Applications-

- In engineering industry.

- In construction industry.

- In Workshop.
}

\section{VI- CONCLUSION}

As per the above discussion, we concluded that to overcome problems in conventional hacksaw machines, due to high efficiency, easy to operate and affordable price the proposed model of multi-way power hacksaw the machine is helpful and completes all the expectations needed for the mini-industries. Future scope of proposed research work to increase the production rate cuts the metal bars easily. It can withstand the vibrations, no hazards from a jerk, no special training required to operate it. After studying this report, we have to know that how the A hacksaw machine will work and knowing the construction and how mechanism work in the machine. We learnt how the theoretical design is possible in practice. Another hacksaw machine is only cut one part at one time but this machine cut the four parts at a time, this hacksaw machine has lighter weight compared to another machine. The cost of the machine is less and easy to operate so it affordable for all industry. The material cast iron which is used will give the high strength than alloy steels. This project is very much useful and easy to install by the user and also the motor used will not only operate with the help of electricity but also through conventional source of energy like solar energy

\section{REFERENCES}

[1]. R. Subhash, C.M. Meenakshi, K. Samuel Jayakaran, C. Venkateshwara, R. Sasidharan, "Fabrication pedal powerHacksaw.

[2]. Peart, G. R. (1902). U.S. Patent No. 706,447. Washington, DC: U.S. Patent and TrademarkOffice.

Martin, J. A., \& Erisoty, G. J. (1998). U.S. Patent Application No. 29/081,671.

[3]. Sawyer, W. G., Diaz, K. I., Hamilton, M. A., \&Micklos, B. (2003). Evaluation of a Model for the Evolution of Wear in a Scotch-Yoke Mechanism. Journal of tribology, 125(3), 678681.

[4]. Budinski, K. G., \& Budinski, M. K. (2009). Engineering materials. Nature, 25, 28.

[5]. Waldherr, A. (1989). U.S. Patent No. 4,835,869. Washington, DC: U.S. Patent and Trademark Office.

[6]. Lipcha, B., Kadam, A., Gadakh, S., Yadav, A., \& Pathan, F. U. RECTIFICATION OF POWER HACKSAW MACHINE.

[7]. Kalpakjian, S., \& Schmid, S. R. (2014). Manufacturing engineering and technology ( $p$. 913). Upper Saddle River, NJ, USA: Pearson 